\title{
Who Pays? Cost-Sharing, Tradeoffs, and the Physicians' Role in Decision Making
}

\author{
Anders Chen, MD, MHS, and Craig Evan Pollack, MD, $\mathrm{MHS}^{1,2}$ \\ 'Johns Hopkins University School of Medicine, Baltimore, MD, USA; ${ }^{2}$ Johns Hopkins Bloomberg School of Public Health, Baltimore, MD, USA.
}

J Gen Intern Med 27(9):1097-9

DOI: $10.1007 / \mathrm{s} 11606-012-2119-0$

(c) Society of General Internal Medicine 2012

I $\mathrm{n}$ this issue of JGIM, Galbraith and colleagues describe the impact of high deductible health plans (HDHPs) on delayed or foregone care amongst families with chronic medical conditions. ${ }^{1}$ They find that families in HDHPs are more likely to delay or forego care, compared to those in traditional plans. Patients in health plans with high out-ofpocket costs and with limited resources must, at times, make real tradeoffs. These tradeoffs raise a number of important questions. When families forgo health care, what are the consequences? When healthcare is not sacrificed, what is? And what should be the role of primary care providers in helping patients and their families face these decisions? In the setting of the rapid uptake of high deductible health plans ${ }^{2}$ and continued economic turbulence, the answers to these questions have become more urgent.

The effects of HDHPs on health care utilization and outcomes are not well established. The RAND Health Insurance Experiment (HIE) in the 1970s suggested that increased cost-sharing generally reduced overall health care utilization and spending, and did not lead to worse health outcomes. This paved the way for insurance plans with higher cost-sharing, and in recent years, HDHPs. However, the effects of RAND's experiment on the health of patients with chronic illnesses were less clear. ${ }^{3},{ }^{4}$ Subsequent to the RAND experiment, a growing body of literature has demonstrated that for patients with chronic illnesses, such foregone care due to cost-sharing indeed may be detrimental. ${ }^{5-11}$ Whether this was true during the RAND HIE and undetected, or whether this has emerged recently due to improved care for chronic illnesses remains unclear. ${ }^{12}$ The specific data on HDHPs are coming to light. Research suggests that HDHPs tend to reduce low acuity ED visits and overall costs. ${ }^{13,14}$ However, it is uncertain whether early reductions will be sustained over time ${ }^{15}$ and what the overall impact will be on health outcomes. Overall, the

Published online June 13, 2012 literature to date raises significant concern that while cost sharing may reduce health care utilization, it is a blunt instrument that may have health consequences for those with chronic disease.

Along with forgoing health care, patients with high health care needs, high out-of-pocket costs, and limited financial resources sacrifice other necessities. Patients make direct tradeoffs between health care, food, housing and other basic needs. ${ }^{16}$ And patients who, for example, skip meals or miss home mortgage payments face greater health challenges as a result. ${ }^{17,} 18$

In the present study, Galbraith and colleagues identify an additional tradeoff that is being made: the health care of one family member for the health care of another. The authors found that in families in which an adult has a chronic illness but the children are healthy, children experience delayed or foregone care. In families in which a child has a chronic illness but the adults are healthy, adults experience delayed or foregone care. This suggests that when families have limited healthcare resources, these resources are pooled across a family. Healthier family members sacrifice for the sicker ones, regardless of age. This 'spillover effect' appears to be an understandable strategy of distributing family resources to those with greatest need.

The emergence of high cost-sharing plans also changes the physician role in advising patients. Traditionally, physicians have acted as agents for patients by making medical decisions on their behalf, without regard to financial constraints. ${ }^{19}$ This has given way to physicians being asked to consider patients' financial circumstances, and thus implicitly the tradeoffs they face. Primary care physicians are reluctant to discuss and consider these factors owing to discomfort, lack of time, and perceived inability to intervene. ${ }^{20}$ However, ethical arguments have been made that they have a duty to do so, in order to serve as the best possible agents. ${ }^{21}$ Subsequent research showed that when physicians did consider out-of-pocket costs in the setting of HDHPs, they made different clinical decisions. ${ }^{22}$

With financial considerations, we began to ask the difficult question of which care to forego? With family spillover repercussions, we now must ask a potentially more difficult question of whose care to forego?

For physicians, understanding these family tradeoffs and preferences serves as a guide to better help patients make 
medical decisions. Indeed it is these tradeoffs and preferences that may redefine the role of the physician as a patient agent. How do families make these decisions for each family member in light of their collective financial situation? Even in the case of family practitioners who may see the whole family, physicians are untrained to fully weigh tradeoffs between family members. They may not want to take on the added responsibility and potential liability of helping families prioritize among themselves. In the context of financial constraints, Alexander and others have argued that the "fiduciary principles of physician agency demand that physicians also consider costs so they can better advise patients..." 20 Though this line of argument can be reasonably extended to include the physician's duty to consider family tradeoffs, more work is needed to help families and their physicians prioritize and address such concerns.

How can we help patients and their families make these difficult choices? One option is to design insurance plans that minimize such tradeoffs in the first place, by having lower cost sharing on high-yield care. ${ }^{12}$ Copayments and deductibles are frequently waived for preventative services in HDHPs. To the extent that waivers from cost sharing preserve their use, this is an important strategy. However, studies have come to mixed conclusions as to whether HDHPs still lead to a reduction in the use of such services, ${ }^{14,23-25}$ and patients and their physicians do not always understand the specifics of their plan design. ${ }^{26}$ Additional research is necessary to determine the optimal way to structure and implement HDHPs - and value based insurance design more generallyto reduce the potential unintended consequences for important clinical services.

In the meantime, physicians need to know if patients are enrolled in plans with high cost sharing, the extent to which out-of-pocket costs are a concern for the individual patient, and whether patients are making trade-offs within families. ${ }^{27}$ Physicians can connect patients with social workers who may be able to help families marshal healthcare and non-healthcare resources. Financial services and counselors that help families better understand financial decision-making are another option. Multi-disciplinary teams would allow patients, family members, physicians, social workers, and financial counselors to work together in a coordinated fashion. Evaluating different care delivery models that help patients address financial tradeoffs is necessary.

Galbraith's article reminds us that patients are not only making tradeoffs among different healthcare choices and between healthcare and non-health care resources, but also healthcare tradeoffs with other family members. These tradeoffs are, in part, driven by high cost-sharing insurance plans such as HDHPs. The associated health outcomes, especially for vulnerable populations, such as those with chronic illnesses and limited resources, remain unclear. In light of these clinical, non-clinical and family tradeoffs, the physician's role as the patient agent continues to evolve, as we are faced with a broader interpretation of medical decision-making.

Acknowledgments: Dr. Chen's salary was supported by a National Research Service Award Grant from the Department of Health and Human Services (2T32HLO07180-36).

Dr. Pollack's salary was supported by a career development award from the NIH National Cancer Institute and Office of Behavioral and Social Sciences Research (K07CA151910).

Conflict of Interest: The authors declare that they do not have a conflict of interest.

Corresponding Author: Anders Chen, MD, MHS; Johns Hopkins University School of Medicine, 2024 E. Monument St, 2-604, Baltimore, MD 21287, USA (e-mail: achen60@jhmi.edu).

\section{REFERENCES}

1. Galbraith AA, Soumerai SB, Ross-Degnan D, et al. Delayed and Forgone Care for Families with Chronic Conditions in High-Deductible Health Plans, J Gen Intern Med. 2012; doi:10.1007/s11606-011-1970-

2. Kaiser Family Foundation and Health Research \& Educational Trust. Survey of Employer Sponsored Benefits, 2011.

3. Leibowitz A, et al. Effect of Cost-Sharing on the Use of Medical Services by Children: Interim Results from a Randomized Controlled Trial. Pediatrics. 1985;75:942.

4. Newhouse, JP. Consumer-directed health plans and the RAND Health Insurance Experiment. Health Aff. 2004 Nov-Dc;23(6):107-13.

5. Chernew ME, et al. Impact of decreasing copayments on medication adherence within a disease management environment. Health Aff. 2008;27(1):103-112.

6. Goldman DP, et al. Prescription drug cost sharing. Associations with medical utilization and spending and health. JAMA. 2007;298(1):61-69.

7. Gibson TB, et al. The effects of prescription drug cost sharing: a review of the evidence. Am J. Manag Care. 2005;11(11):730-740.

8. Choudhry NK, et al. Full coverage for preventive medications after myocardial infarction. N Engl J Med. 2011;365(22):2088-97.

9. Hsu $\mathbf{J}$, et al. Unintended consequences of caps on Medicare drug benefits. N Engl. J. Med. 2006;354(22):2349-2359.

10. Chandra, A. et al. Patient Cost-Sharing, Hospitalization Offsets, and the Design of Optimal health Insurance for the Elderly. Cambridge, MA: National Bureau of economic Research; 2007. Working paper W12972

11. Tamblyn R, et al. Adverse events associated with prescription drug costsharing among poor and elderly persons. JAMA. 2001;285(4):421-429.

12. Chernew ME, Newhouse JP. What does the RAND Health Insurance Experiment tell us about the impact of patient cost sharing on health outcomes? Am J Manag Care. 2008;14(9):618-9.

13. Wharam JF, et al. Emegency Department Use and Subsequent Hospitalization Among Members of a High-Deductible Health Plan. JAMA. 2007;297:1093-1102.

14. Buntin MB, et al. Healthcare Spending and Preventive Care in HighDeductible and Consumer-Directed Health Plans. Am J Managed Care. 2011;17(3):222-230.

15. Wharam JF, et al. High-Deductible Insurance: Two-Year Emergency Department and Hospital Use. Am J Manag Care. 2011;17:e410-e418.

16. Cunningham PJ, et al. Living on the edge: health care expenses strain family budgets. Res Briefs. 2008;10:1-14.

17. Seligman HK, et al. Hunger and socioeconomic disparities in chronic disease. N Engl J Med. 2010;363:6-9.

18. Alley $\mathbf{D}$, et al. Mortgage delinquency and public health: Two-year change in depressive symptoms and access to health-relevant resources in a nationally representative cohort of Americans over 50 years old. Am J Publ Health. 2011;101:2293-2298. 
19. Beauchamp, T. L. and J. F. Childress. 1979. Principles of biomedical ethics, First edition. New York, NY; Oxford University Press.

20. Alexander GC, et al. Barriers to Patient-physician Communication About Out-of-pocket Costs. J Gen Intern Med. 2004;19:856-860.

21. Alexander, GC et al. Rethinking Professional Ethics in the Cost-Sharing Era. Am J Bioeth. 2006. Jul-Aug;6(4):W17-22

22. Pollack C, et al. The Impact of Consumer-Directed Health Plans and Patient Socioeconomic Status on Physician Recommendations for Colorectal Cancer Screening. J Gen Intern Med. 2008;23(10):1595-601.

23. Wharam JF, et al. Two Year Trends in Colorectal Cancer Screening After Switch to a High-Deductible Health Plan. Med Care. 2011;49:865-871.
24. Rowe JW, et al. The Effect of Consumer-Directed Health Plans on the Use of Preventative and Chronic Illness Services. Health Aff. 2008;27:113-120.

25. Wharam JF, et al. Cancer Screening before and after Switching to A High-Deductible Health Plan. Ann Intern Med. 2008;148:647655.

26. Kullgren JT, et al. Health Care Use and Decision Making Among LowerIncome Families in High-Deductible Health Plans. Arch Intern Med. 2010;170:1918-1925.

27. Alexander GC, et al. Physican Strategies to Reduce Patients' Out-ofpocket Prescription Costs. Arch Intern Med. 2005;165:633-636. 